\title{
Portosystemic Shunting in Superior Vena Cava Obstruction by Tumor Demonstrated on Ventilation-Perfusion Lung Scan
}

\author{
Seung Wook Ryu, Adrian Waugh, and Kevin C. Allman \\ Department of PET/Nuclear Medicine, Royal Prince Alfred Hospital, University of Sydney, Sydney, Australia
}

\begin{abstract}
Extrapulmonary deposition of macroaggregated albumin particles on lung perfusion scintigraphy occurs in the presence of right-to-left shunting, as demonstrated in this case of portosystemic shunting related to superior vena cava obstruction by germ cell tumor of the mediastinum. The case demonstrates the importance of examining tracer deposition within the entire field of view on $99 \mathrm{mTc}$-macroaggregated albumin perfusion lung scintigraphy for extrapulmonary findings.
\end{abstract}

Key Words: hepatology; respiratory; vascular; lung scan; obstruction; portosystemic shunting

J Nucl Med Technol 2014; 42:118-119

DOI: 10.2967/jnmt.113.131375

$\mathbf{E}$ xtrapulmonary deposition of macroaggregated albumin particles on lung perfusion scintigraphy occurs in the presence of right-to-left shunting. We present a case of portosystemic shunting related to superior vena cava obstruction by germ cell tumor of the mediastinum.

\section{CASE REPORT}

A 21-y-old man presented with pleurisy and dyspnea. Ventilation-perfusion lung scintigraphy was performed to evaluate for possible pulmonary embolism. Four months earlier, a large nonseminomatous germ cell tumor had been diagnosed in the right mediastinum, and there was known superior vena cava obstruction and lung metastases. The patient had recently completed 4 cycles of bleomycin chemotherapy. Scintigraphy showed hepatic deposition of ${ }^{99 \mathrm{~m}} \mathrm{Tc}$-macroaggregated albumin on perfusion imaging, indicating development of portosystemic shunting by collateral pathways.

Scintigraphy was performed with ${ }^{99 \mathrm{~m}} \mathrm{Tc}$-labeled carbon (Technegas; Cyclomedica Ltd.) and with $173 \mathrm{MBq}(4.7$ $\mathrm{mCi})$ of ${ }^{99 \mathrm{~m}} \mathrm{Tc}-$ macroaggregated albumin injected intrave-

\footnotetext{
Received Aug. 20, 2013; revision accepted Nov. 11, 2013.

For correspondence or reprints contact: Seung Wook Ryu, Department of PET/Nuclear Medicine, Royal Prince Alfred Hospital, Building 63, Level A7, Missenden Rd., Camperdown, NSW, 2050, Australia.

E-mail: swk.ryu@gmail.com

Published online Feb. 20, 2014.

COPYRIGHT (c) 2014 by the Society of Nuclear Medicine and Molecular Imaging, Inc.
}

nously. Matched defects were seen in the right oblique fissure and in the left lung base (Fig. 1), which were due to the right mediastinal tumor and left pleural effusion, respectively, as seen on chest radiography (not shown). Abnormal tracer accumulation seen in the right abdomen anteriorly in the liver (Fig. 1) was due to the portosystemic shunting via collateral pathways secondary to the superior vena cava obstruction.

CT pulmonary angiography demonstrated the superior vena cava thrombus and the large right anterior mediastinal tumor (Fig. 2). The nearly occlusive thrombus in the superior vena cava extended into the right subclavian, right internal jugular, and left brachiocephalic veins. Extensive collateral pathways were visible in the right chest wall and neck, which shunted the systemic venous blood flow back to the right atrium. The CT pulmonary angiogram

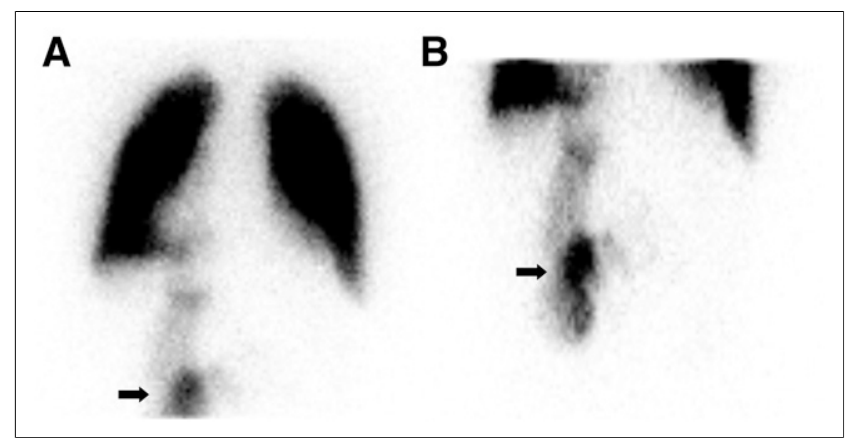

FIGURE 1. Perfusion images of anterior chest $(A)$ and abdomen (B), with arrows indicating large portosystemic shunt.

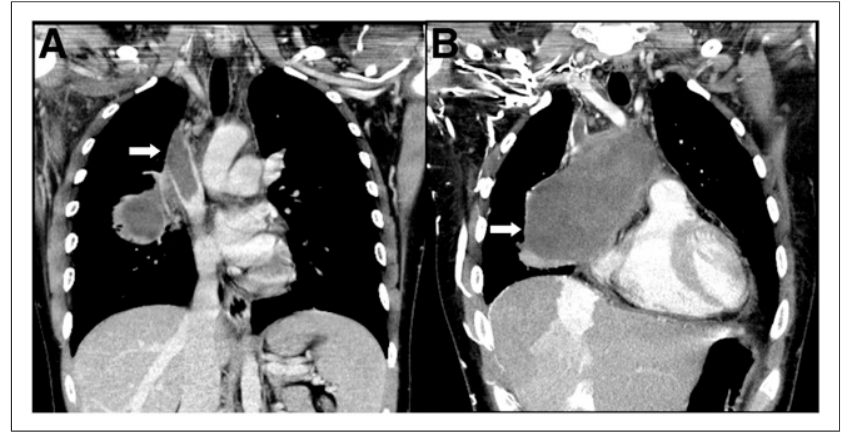

FIGURE 2. Coronal slices of CT pulmonary angiogram showing superior vena cava thrombus (arrow, A) and mediastinal tumor (arrow, B). 
showed no evidence of pulmonary embolism. Clinical features of superior vena cava syndrome were evident only before commencement of chemotherapy. The patient had been on long-term anticoagulation treatment with subcutaneous low-molecular-weight heparin.

\section{DISCUSSION}

Hepatic uptake of ${ }^{99 \mathrm{~m}}$ Tc-macroaggregated albumin has been reported in both superior and inferior vena cava obstructions (1-4) and is caused by shunting of venous blood flow through collateral pathways to the portal system. Superior vena cava obstructions are usually due to malignancy $(2-4)$ but are also seen infrequently in benign conditions such as inflammation, trauma, coagulopathies, and indwelling catheters with insidious progression allowing various collateral pathways to develop (5). These pathways in superior vena cava obstruction have been well described (2-5) and include the azygous and hemiazygous, superior and inferior intercostal, internal mammary, lateral thoracic, epigastric, and vertebral veins. In our case, collateral pathways over the chest wall and upper abdomen were evident, indicating involvement of the azygous system (2). These pathways drain through either the umbilical or the paraumbilical veins, which shunt mostly into the left main branch of the portal vein and result in visualization of the left hepatic lobe. The contrast enhancement of segments $4 \mathrm{a}$ and $4 \mathrm{~b}$ of the liver on CT corresponded to the scintigraphic findings (Fig. 3). In the case presented, the shunt was large.

\section{CONCLUSION}

This case illustrates a large shunt and demonstrates the importance of examining tracer deposition within the entire field of view on ${ }^{99 m}$ Tc-macroaggregated al-

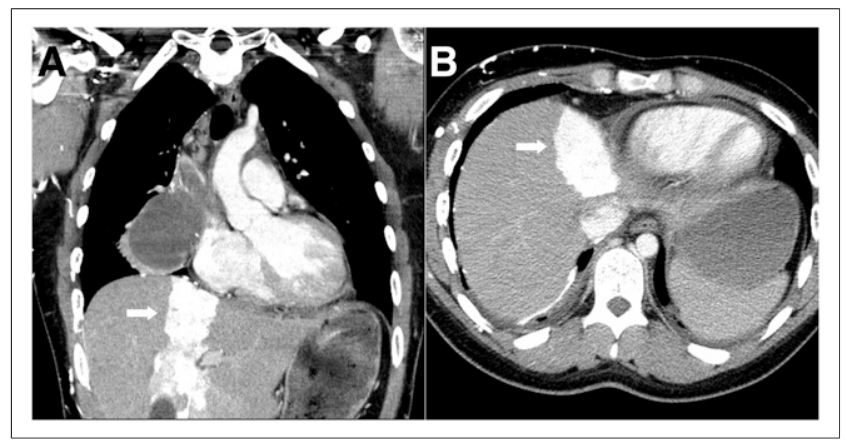

FIGURE 3. CT pulmonary angiogram on which coronal $(A)$ and transverse (B) slices demonstrate liver enhancement (arrows).

bumin perfusion lung scintigraphy for extrapulmonary findings.

\section{DISCLOSURE}

No potential conflict of interest relevant to this article was reported.

\section{REFERENCES}

1. Balink H, Nabers J. Periumbilical uptake of Tc-99m MAA on lung perfusion scanning in a patient with superior vena cava obstruction. Clin Nucl Med. 2006;31:215-217.

2. Esser JP, Oei HY, de Bruin HG, Krenning EP. Liver and vertebral uptake of Tc99m macroaggregated albumin (MAA). Clin Nucl Med. 2004;29:793-794.

3. Nguyen BD, Roarke MC. Superior vena cava obstruction with intrahepatic and systemic-pulmonary venous right-to-left shunts. Clin Nucl Med. 2004;29:491-493.

4. Schwartz M, Swayne LC, Macaulay RD, Schwartz JR. Lung scan detection of SVC clot with collateral flow to liver. J Nucl Med. 1996;37:1826-1827.

5. Mackie GC, Thomas A, Greenspan B, Singh A. Focal hepatic activity during ventilation-perfusion scintigraphy due to systemic-portal shunt due to superior vena cava obstruction from histoplasmosis-induced fibrosing mediastinitis. Clin Nucl Med. 2007;32:707-710. 